\title{
NOTAS ACERCA DE LA FORMACIÓN HISTÓRICA DE LA CIENCIA DEL DERECHO ECLESIASTICO
}

\author{
Lourdes Ruano Espina \\ Profesora Titular de Derecho Canónico y Eclesiástico del Estado \\ Universidad de Salamanca
}

\begin{abstract}
RESUMEN
Si durante siglos el Derecho Eclesiástico se identificó con el conjunto de normas emanadas de la Iglesia Católica, considerándose como sinónimo del Derecho Canónico, el proceso histórico de formación del mismo se iniciaría cuando el Estado se considera legitimado para legislar en materias eclesiásticas, defendiendo su propia soberanía frente al monopolio de la competencia del Derecho de la Iglesia, hasta entonces pacíficamente reconocido, fenómeno que se produjo de forma diversa en los países católicos que en aquellos en que triunfó la reforma protestante. Su consolidación como Ciencia jurídica autónoma, primero en Italia y, posteriormente en España, desde la perspectiva actual del Estado moderno, no se explica ya, sin embargo, como el fruto de un intervencionismo estatal en materia religiosa sino sobre la base del reconocimiento, tutela y promoción de los derechos humanos y, en particular, del derecho de libertad religiosa.
\end{abstract}

Palabras clave: Derecho Eclesiástico, Derecho Canónico, Iglesia, Estado, Factor religioso, Libertad religiosa.

\begin{abstract}
If the historical training process of the Ecclesiastic Law was begun when the State was considered legitimated to legislate in ecclesiastic matters, defending its own front sovereignty against the monopoly of the domain of the Law of the Church, at present, its consolidation as autonomous legal Science has been possible thanks to the recognition, tutela and promotion of the human rights and, in particular, of the right to religious freedom.
\end{abstract}

Key words: Ecclesiastic Law, Church, State, Religious freedom.

\section{PRESUPUESTOS PREVIOS: LA APARICIÓN DEL ESTADO MODERNO}

Con independencia de la opinión particular que se tenga acerca del objeto de estudio de la Ciencia del Derecho Eclesiástico del Estado, en la actualidad parece una cuestión incontestable que dicha Ciencia es una rama del ordenamiento jurídico del Estado, que en nuestros días goza de una cierta autonomía y reconocimiento como rama jurídica autónoma. Es fácilmente comprensible, entonces, que presupuesto histórico de su aparición y existencia sea el nacimiento del Estado moderno. Aunque el origen más remoto del Estado moderno se sitúa en torno a los siglos XIV y XV, como consecuencia de las intervenciones de los Estados nacionales en materia eclesiástica, su consolidación tiene lugar a partir de las monarquías absolutas y el consiguiente resquebrajamiento del sistema hierocrático que había caracterizado el orden políti- 
co medieval ${ }^{1}$. El absolutismo del poder del monarca se defendió también frente al papado, no sólo cuestionando la función que el Papa había venido desempeñando en el orden político de la cristiandad medieval, sino incluso de las autoridades eclesiásticas, en materias relativas al orden interno de la Iglesia. De ahí que, como ha afirmado P. LOMBARDIA, «el fenómeno del Derecho Eclesiástico del Estado implicó, desde sus orígenes, un desconocimiento por parte del poder civil de la exclusiva competencia eclesiástica para el gobierno de las cuestiones de índole religiosa», de modo que puede afirmarse que «el desarrollo del Derecho Eclesiástico estatal ha significado un progresivo debilitamiento del reconocimiento, por parte del poder temporal, del principio del dualismo cristiano ${ }^{2}$.

Este fenómeno se produjo de forma diversa en los países católicos que en aquellos en que triunfó la reforma protestante. En los primeros se conservó la concepción dualista del poder y se respetó la función del Papa y los Obispos en el gobierno de la Iglesia, si bien la intervención estatal en materia religiosa fue incrementándose progresivamente. En los países en que triunfó la reforma protestante, el planteamiento dualista se descompensó en favor del poder estatal, al entrar en crisis la idea de una Iglesia jerárquica. La concepción del Estado como poder secularizado y omnímodo sobre todas las cosas, el debilitamiento de uno de los polos del planteamiento dualista, el religioso o eclesiástico, llevó al Estado a arrogarse el derecho de regular la vida religiosa de los ciudadanos.

Hay que señalar que desde la perspectiva actual del Estado moderno la explicación de la existencia del Derecho Eclesiástico es muy distinta. Las normas jurídicas que el Estado dicta en materia religiosa no constituyen el fruto de un intervencionismo estatal sino que más bien las tendencias secularizadoras han llevado a los Estados a declararse incompetentes en materia religiosa, a la vez que, sobre la base de la aceptación del principio del respeto a los derechos humanos, los ordenamientos estatales reconocen y tutelan el derecho de libertad religiosa, atribuyendo de este modo un ámbito de autonomía a las actividades religiosas individuales y colectivas ${ }^{3}$.

\section{DE LA ESCUELA RACIONALISTA A LA ESCUELA HISTÓRICA}

Durante siglos, el Derecho Eclesiástico se identificó con el conjunto de normas emanadas de la Iglesia católica, considerándose como sinónimo del Derechọo Canónico ${ }^{4}$. Esta identifica-

1 Como ha señalado el Profesor LOMBARDIA, si la materia de estudio del Derecho Eclesiástico está constituida por las disposiciones que adopta el poder del Estado para regular la incidencia social de los fenómenos relacionados con la dimensión religiosa de la vida de los hombres, no es un azar de la historia que en el plano del Derecho positivo los más remotos orígenes del Derecho Eclesiástico haya que situarlos en el siglo XIV, cuando el Estado moderno empieza a perfilarse, al calor del naciente espíritu laico, en fuerte contraste con el hierocratismo medieval. Cf. La Presentación a la obra de J.J. AMOROS AZPILICUETA, La libertad religiosa en la Constitución española de 1978 (Madrid 1984) 13-14.

2 «El Derecho Eclesiástico del Estado español», en Derecho Eclesiástico del Estado Español (Pamplona 1983) 90. Cf. los estudios del mismo autor, «Derecho Eclesiástico y libertad religiosa», en Revista de Derecho Público 9, vol. 1 (1983); Escritos de Derecho Canónico y Derecho Eclesiástico del Estado 5 (Pamplona 1991) 139 ss. Desde este punto de vista, afirma el profesor J.J. AMOROS AZPILICUETA que el origen del Derecho Eclesiástico está conectado íntimamente a la idea de laicidad del Estado, al proceso de secularización y desclericalización del Estado. «Secularización y laicidad son, en este sentido, puntos de partida para la formación del Derecho Eclesiástico»: «La ciencia del Derecho Eclesiástico y los factores de su evolución» IC 23 (1983) 342 y 347.

3 P. LOMBARDIA, «El Derecho Eclesiástico..»., p. 91.

4 Ha sido sin duda L. DE LUCA quien con mayor profundidad ha analizado la evolución conceptual del Derecho Eclesiástico, en su obra Diritto Ecclesiastico ed esperienza giuridica (Milano 1970). Cf. También F. FINOCCHIARO, «Lo studio del Diritto Ecclesiastico negli ultimi venti anni», DE 92 (1981) 529; M. CONDORELLI, «Diritto Eclesiastico e storia giuridica nell'esperienza italiana», Storia e dogmatica nella scienza del Diritto Ecclesiastico (Milano 1982) 127 ss. 
ción es perfectamente comprensible si se tiene en cuenta que para el planteamiento iusnaturalista medieval, o si se quiere, para la concepción tomista del Derecho, el orden jurídico es parte esencial del orden moral, de modo que una norma jurídica sólo es tal cuando está de acuerdo con los preceptos de Derecho divino, natural o positivo. En caso contrario, carecerá de la necesaria rationabilitas y por consiguiente no será ya ley sino legis corruptio. Por Derecho divino positivo el gobierno de los hombres se entendía distribuido entre el poder espiritual o eclesiástico y el temporal o estatal y era a aquel a quien lógicamente correspondía la regulación de las materias eclesiásticas. Un planteamiento distinto sólo sería posible cuando «el orden jurídico temporal se explicara sobre bases distintas, en las que no se incluyera una apelación al Derecho divino positivo».

Esta plataforma ideológica la propició la Escuela racionalista del Derecho natural, que propone el estudio de los problemas fundamentales del orden jurídico a la sola luz de la razón y —en términos de GROCIO- como si Dios no existiera ${ }^{5}$. Bajo la influencia del iusnaturalismo racionalista de PUFENDORF y THOMASIO, y en un clima teológico protestante, surge en el siglo XVIII en Alemania la Escuela del Derecho Eclesiástico natural de Halle, para la cual los conceptos de Iglesia y Derecho Eclesiástico no deben deducirse del Derecho positivo sino de esquemas abstractos, apriorísticamente elaborados por la razón ${ }^{6}$. Como algún autor ha puesto de manifiesto, nos encontramos, por primera vez, con una Ciencia del Derecho Eclesiástico que no es ya la del Derecho de la Iglesia, pero tampoco la del Derecho del Estado absoluto, frente al que se adopta una actitud muy crítica desde la perspectiva de la razón ${ }^{7}$. El Derecho natural pasa a convertirse en el fundamento del Derecho Eclesiástico, surgiendo entonces la Ciencia del Derecho Eclesiástico natural, a partir de un método deductivo que pretende elaborar un sistema completo del Derecho Eclesiástico basado en deducciones de la razón. Este Derecho Eclesiástico es racional, es unitario, eterno, inmutable y tiene perenne validez ${ }^{8}$.

Esta concepción del Derecho Eclesiástico como Derecho relativo a la materia eclesiástica, desde la perspectiva de la razón, es lo que DE LUCA ha denominado concepción monista del Derecho Eclesiástico. La unidad del sistema del Derecho Eclesiástico viene dada por razón del objeto-derecho sobre la materia religiosa pero también por razón de la fuente, «puesto que la fuente principal de este Derecho de fundamentación iusnaturalista es la razón, y de modo inmediato la autoridad civil, que sería la única competente para establecer normas jurídicas en el fuero externo» ${ }^{9}$. El Derecho Eclesiástico se concibe, así, como una rama del Derecho que tiene por objeto la materia eclesiástica, y que prescinde de la fuente legislativa, eclesiástica o civil, que emana dichas normas.

Esta visión unitaria de la Ciencia del Derecho Eclesiástico y su identificación en razón de la materia recibió un extraordinario impulso como consecuencia de la aplicación de los pos-

5 «Etiam si daremus...non esse Deum», expresión utilizada por H. GROCIO en los Prolegomena de su obra De jure belli ac pacis (Amsterdam 1646) fol. 5, recto.

6 Cf. L. DE LUCA, Il concetto del Diritto Ecclesiastico nel suo sviluppo storico (Padova 1946) 35 ss.; Id., Diritto Ecclesiastico... 10 ss.

7 J.J. AMOROS AZPILICUETA, «La Ciencia del Derecho Eclesiástico y los factores de su evolución» IC 23 (1983) 354. Entiendo que por error de imprenta, el trabajo citado aparece publicado, en su título inicial como la Ciencia del Derecho canónico...

8 Cf. E. MOLANO, Introducción al estudio del Derecho Canónico y del Derecho Eclesiástico del Estado (Barcelona 1984) 194-95; A. REINA y V. REINA, Lecciones de Derecho Eclesiástico Español (Barcelona 1983) 132-33.

9 E. MOLANO, Introducción al estudio... 195. Como el mismo autor señala, es conveniente recordar que el planteamiento monista de las fuentes del Derecho Eclesiástico en esta época es más bien propio de los juristas protestantes, pues entre los juristas católicos no se dejó de reconocer la existencia de un Derecho Canónico junto a los derechos circa sacra de la autoridad civil. Así, por ejemplo, la Escuela de Wurzburgo, que coincide con la Escuela de Halle en la fundamentación iusnaturalista del Derecho, distingue sin embargo diversidad de fuentes, canónicas y civiles, a la hora de considerar el Derecho positivo. 
tulados de la Escuela histórica del Derecho. Como indica LOMBARDIA, sobre la base de los planteamientos de esta Escuela se llegaría, principalmente en Alemania, a la construcción de un sistema de Derecho Eclesiástico en el que se integraban los datos de Derecho positivo tanto de procedencia eclesiástica (católica o protestante) como de procedencia estatal ${ }^{10}$. La Escuela histórica, cuyo presupuesto principal lo constituye el Volksgeists, el espíritu del pueblo adoptado por SAVIGNY como criterio de configuración y explicación del Derecho, se encuadra en el ámbito del movimiento romántico y de filosofía idealista de SCHELING y HEGEL, y surge como reacción contra un Derecho natural racionalista, abstracto y egocéntrico ${ }^{11}$. Para Savigny -afirmaba RECASENS en el año $1961^{12}$ _ no tiene sentido querer oponer al Derecho histórico un supuesto Derecho natural, construido con la razón abstracta. Los ideales jurídicos no podemos construirlos intelectualmente, sino que hay que recogerlos de la realidad de la conciencia nacional espontánea. El Derecho no puede idearse en un gabinete de especulaciones racionales, sino que es el producto del espíritu colectivo de cada pueblo.

Para la Escuela histórica el Derecho no tiene un valor absoluto e inmutable, como defendía la concepción iusnaturalista, sino que por el contrario el Derecho se concibe como un hecho social, un producto de la historia. «Il diritto - afirma DE LUCA retomando las palabras de VANNI- nato ed elaborato in seno alla coscienza di un popolo in relazione ed armonia con tutti gli altri elementi di civiltà, vario quindi secondo i luoghi e le condizioni sociali, vive, si sviluppa, si trasforma nella continuità della storia» ${ }^{13}$. A la concepción estática del Derecho, propia de la Escuela del Derecho natural, la Escuela histórica contrapone una concepción dinámica del Derecho, en cuanto que éste es considerado como el producto de una contínua evolución. El Derecho se concibe, pues, según el propio SAVIGNY, como algo que deriva de la más alta naturaleza del pueblo y que cambia, se desarrolla y evoluciona perennemente ${ }^{14}$.

Desde esta perspectiva, el Derecho Eclesiástico es una rama del Derecho que se identifica no por la fuente sino por la materia: es el Derecho que se refiere al fenómeno religioso y cuyo objeto es lo eclesiástico. Se trata de un Derecho cambiante, mudable, como la misma historia. De esta forma, como podemos ver, la Escuela histórica refuerza la concepción monista del Derecho, propia de la Escuela racionalista del Derecho natural, pero partiendo de postulados distintos e incluso contradictorios. En síntesis, como afirma J. FORNES, «al criterio de la materia la Escuela histórica añadirá la característica de la vigencia, que se apoya radicalmente en las coordenadas de lugar y tiempo. Derecho Eclesiástico será aquel Derecho que - provenga de la fuente que provenga: Iglesia católica, confesiones protestantes, Estado- tiene por objeto la materia religiosa y está vigente en ese momento histórico en un país determinado " ${ }^{15}$.

Este criterio identificador del Derecho Eclesiástico, precisamente el objeto de su ciencia, la materia o Derecho Eclesiástico vigente en un lugar y momento determinados, resulta de vital importancia para los eclesiasticistas alemanes, como E.L. RICHTER, o sus alumnos y seguidores, como E. FRIEDBERG, P. HINSCHIUS, J. F. VON SCHULTE, DOVE, MEJER, etc., que prescindiendo de todo tipo de juicios apriorísticos parten de un planteamiento aconfesional y de objetividad científica. No se trata ya, pues, de valorar, a la luz de los principios dogmáticos presupuestos, como hacían los iusnaturalistas, la juridicidad de determinadas normas, sino simplemente de exponer, prescindiendo de todo tipo de apreciación personal, lo que his-

10 «El Derecho Eclesiástico..». 93.

11 L. DE LUCA, Il concetto... 51; Diritto Ecclesiastico... 23-24.

12 Tratado General de Filosofia del Derecho (México 1961) 439-43.

13 Diritto Ecclesiastico... 24. Cf. VANNI, «I giuristi della scuola storica di Germania nella storia della sociologia e della filosofia positiva», Riv. di Filosofia scientifica IV (1885) ${ }^{-12}$.

14 Cf. E. MOLANO, Introducción al estudio... 194-95; A. REINA y V. REINA, Lecciones de Derecho Eclesiástico, 132-33.

15 J. FORNES, La ciencia canónica contemporánea. Valoración crítica (Pamplona 1984). 33. 
tóricamente se afirma como Derecho, en el ámbito de un determinado territorio y de un determinado pueblo ${ }^{16}$.

\section{LA INFLUENCIA DEL POSITIVISMO JURÍDICO}

La configuración integral del concepto monista del Derecho Eclesiástico se dará con el apogeo del positivismo jurídico. En efecto, la incidencia de la filosofía de AUGUSTO COMPTE en el ámbito del Derecho llevaría consigo la consideración de la Ciencia jurídica como Ciencia del Derecho positivo. Al trasladar el principio de causalidad, propio de las ciencias naturales, al campo jurídico, la doctrina jurídica centrará su atención en la importancia de las fuentes legislativas como causa directa y concreta del Derecho y prescindirá de las exigencias naturales. Derecho sólo será, desde esta perspectiva, lo que está en la ley, lo que es ley y no lo que debe ser. La consecuencia inmediata es evidente: sólo se considera Derecho el que tiene efectividad, el que está vinculado a su única causa eficiente y necesaria: el Estado ${ }^{17}$.

Para este movimiento el Estado es la única fuente posible del Derecho y sólo se consideran como jurídicas aquellas normas que emanan de la autoridad civil, porque el Derecho, para tener existencia real, necesita una fuerza que le otorgue eficacia y que obligue a todos, y esa fuerza sólo puede radicar en el Estado. Esta concepción del Derecho reforzó indudablemente el planteamiento monista del Derecho Eclesiástico, pues éste no sólo se especifica ya ratione materiae sino al mismo tiempo ratione fontis. El Derecho Eclesiástico sería pues el conjunto de normas jurídicas dictadas por el Estado para regular la materia eclesiástica ${ }^{18}$. El Derecho Eclesiástico será monista no sólo por razón de la materia, sino también por su fuente, el Estado. Este monismo positivista pone de manifiesto un planteamiento y una concepción de nuestra disciplina radicalmente inversa a la vigente en la Edad Media. Para el monismo medieval el Derecho Eclesiástico era el Derecho de la Iglesia, mientras que para el positivismo jurídico el Derecho Eclesiástico es el Derecho del Estado sobre la materia religiosa.

Esta nueva concepción supondrá la negación del carácter jurídico de todas aquellas normas de origen confesional, y en particular las normas de Derecho Canónico, cuya juridicidad dependerá del previo reconocimiento que de ellas haga el Estado. Como afirmó O. MEJER, las normas dictadas por la Iglesia sólo pueden considerarse jurídicas cuando su aplicación sea impuesta coactivamente por el Estado ${ }^{19}$. Cabría afirmar, según lo expuesto, que en realidad el positivismo jurídico admitió la existencia de otras fuentes del Derecho distintas al Estado, pero sólo en sentido relativo porque aquellas sólo se consideran fuentes en cuanto que proporcionan a éste el material necesario para que el Estado dicte sus normas jurídicas. Y en este sentido también la Iglesia podría considerarse fuente, aunque sólo en sentido material. Es conocida a este respecto la significativa frase de MEJER: «creo poder considerar como principio hoy generalmente admitido la siguiente afirmación: no sólo no cabe concebir el Estado sin el Derecho, sino que tampoco cabe el Derecho sin el Estado» ${ }^{20}$.

Estos planteamientos, que surgen en Alemania, pasarian pronto a Italia. Entre los máximos representantes de este movimiento en Italia cabe señalar a SCHIAPPOLI, que si bien distinguió entre Derecho Eclesiástico del Estado y de la Iglesia, concebía como Derecho sólo

16 L. DE LUCA, Diritto Ecclesiastico... 39.

17 A. REINA y V. REINA, Lecciones de Derecho Eclesiástico español, 136; F. DE P. VERA URBANO, Derecho Eclesiástico I (Madrid 1990) 275.

18 P. LOMBARDIA, «El Derecho Eclesiástico..». 95.

19 Lehrbuch des deutschen Kirchenrechtes (Göttingen 1869) p. 6 y 258, nota 10, cit. por P. LOMBARDIA, loc. cit., p. 95.

20 Ist das Recht einer freien Vereinskirche Recht im juristischen Sinne?, en ZKR XI (1873) 304, cit. por L. DE LUCA, Diritto Ecclesiastico... p. 60. 
aquel que emana del Estado. El Estado, para él, es la única fuente posible del Derecho desde el punto de vista formal. El Estado es el único sujeto de Derecho y su función es formularlo y asegurarse de su observancia coactivamente. El Derecho de la Iglesia puede considerarse como Derecho objetivo sólo en tanto en cuanto sea impuesto o sancionado por el Estado ${ }^{21}$. C. MANENTI, en un discurso pronunciado en 1892, afirmaba que la Iglesia ha cesado de ser fuente de Derecho, y declaraba que «di una fonte ecclesiastica del Diritto Ecclesiastico può parlarsi solo per comodo di esposizione, ma sempre in senso improprio... oggimai fonte di diritto non può essere che lo Stato ${ }^{22}$. Así mismo podemos citar, como claros exponentes de esta teoría en Italia, a SIMONCELLI, OLMO, etc ${ }^{23}$.

Particular confirmación de la tesis estatalista del Derecho constituye la obra que DEL GIUDICE dedicó a la definición del sistema del Derecho Eclesiástico en sentido moderno, en $1915^{24}$. En su monografía parece evidente la adhesión por parte del autor a la teoría del positivismo jurídico, bien sea en el modo de concebir el Derecho, bien lo sea en el método. Habiendo negado el carácter jurídico de las normas emanadas de la Iglesia, para DEL GIUDICE carece de sentido insistir en el concepto unitario del Derecho Eclesiástico, tal como defendían los juristas pertenecientes a la escuela histórica del Derecho, en el que tenían cabida tanto las normas canónicas como las estatales en materia eclesiástica. El Derecho Eclesiástico debe ser concebido, sí, en modo unitario, pero tal unicidad depende del hecho de que no existe Derecho fuera de aquel que proclama el Estado; por esta razón, el concepto de Derecho Eclesiástico debe ser delimitado, según el autor, solamente sobre la base del criterio del objeto, siendo única la fuente del Derecho.

La negación de la juridicidad de las normas emanadas de la Iglesia tuvo un particular exponente en R. SOHM. Desde un ángulo de visión considerablemente diverso a los autores anteriormente citados, SOHM llegó a la misma conclusión. Para él existe una intrínseca incompatibilidad entre Derecho e Iglesia. La Iglesia no es un concepto jurídico sino tan sólo religioso, no es una comunidad coactiva, «la vera Chiesa, la Chiesa di Cristo, non conosce nessun diritto» ${ }^{25}$.

\section{LA ESCUELA ITALIANA. RECEPCIÓN DEL DERECHO ECLESIÁSTICO EN ITALIA: RUFFINI Y SCADUTO}

El estudio de la disciplina de Derecho Eclesiástico en las'universidades italianas tiene lugar en la época del movimiento político de unidad italiana que alcanza su cima en 1870, con la conquista de los Estados Pontificios: el Risorgimento. De alguna forma esta nueva disciplina venía a colmar el vacío causado como consecuencia de la supresión de las enseñanzas de Derecho Canónico en un ambiente laicista y reaccionario contra el pontificado. Así, mientras el Derecho Canónico queda relegado a los seminarios y universidades pontificias, como un símbolo de la defensa de las tesis del Papa, el Derecho Eclesiástico venía a representar la defensa de la Italia unitaria y liberal, se convierte en un instrumento para reivindicar los derechos del Estado frente a la Iglesia y aparece teñido de un matiz anticlerical ${ }^{26}$. Sus cultivadores, en su ma-

21 Lezioni di Diritto Ecclesiastico (Napoli 1921) 6. Cf. También L'indirizzo odierno del Diritto Ecclesiastico in Italia (Napoli 1986).

22 Concetto ed importanza dello studio del Diritto Ecclesiastico. Discurso pronunciado el 20 de noviembre de 1892, para la inauguración del año académico de la Universidad de Macerata (Macerata 1892) 49-51.

23 Un análisis de la exposición de la teoría particular de cada uno de estos autores puede verse en L. DE LUCA, $1 l$ concetto... 91 ss.; Diritto Ecclesiastico...68 ss.

24 V. DEL GIUDICE, Il Diritto Ecclesiastico in senso moderno. Definizione e sistema (Roma 1915).

25 Kirchenrecht I. Bd., Die geschichtlichen Grundlagen (München und Leipzig 1923) 459. Una exposición más detenida de la obra de SOHM sobre este punto puede verse en L. DE LUCA, Diritto Ecclesiastico... 73-75.

26 E. MOLANO, Introducción al estudio... 197. 
yoría no católicos o cuanto menos críticos de la Iglesia católica, se precian de ser verdaderos juristas del Estado.

Desde el punto de vista del método, como ha señalado LOMBARDIA, la escuela italiana «va a arrancar de las bases que le ofrecían los últimos representates de la escuela histórica y las aludidas del positivismo estatalista; pero enseguida adquirirá una personalidad propia, gracias al talante científico de un conjunto de autores, que en definitiva dependen del magisterio de los maestros FRANCESCO RUFFINI y FRANCESCO SCADUTO» ${ }^{27}$.

RUFFINI es, en términos de DE LUCA, el más eficaz intermediario entre la escuela histórica eclesiasticista alemana y la nueva ciencia eclesiasticista italiana ${ }^{28}$. Se había formado en Alemania, en la escuela histórica del Derecho. En 1891 asistió a los cursos que impartía E. FRIEDBERG en la Universidad de Leipzig y en 1893 publica una traducción al italiano del conocido Lehrbuch de su maestro ${ }^{29}$. Como explica en el prefacio de esta traducción, el Derecho Eclesiástico consta de dos partes: un Derecho Eclesiástico que emana del Estado y otro que deriva de la Iglesia y que se identifica con el Derecho Canónico. Según el autor, el primero ha cobrado un gran impulso en los últimos años en Italia gracias al profesor SCADUTO, mientras que la literatura canónica, en los últimos tiempos, sólo ha alcanzado un nivel rudimentario. Sin embargo le parece excelente la literatura canónica alemana, y ésta es la razón principal por la que considera oportuno traducir a FRIEDBERG. Como afirma GONZALEZ DEL VALLE, no son, pues, la parte del Derecho evangélico ni la del Derecho alemán las que interesan a Ruffini, que de hecho son resumidas, con la aquiescencia del autor, en su traducción, sino la parte de Derecho Canónico ${ }^{30}$.

Su interés por construir una ciencia que integre los elementos normativos, tanto de procedencia estatal como de origen eclesiástico, católico o protestante, y su personal convicción de que los problemas jurídicos no pueden encontrar soluciones concretas si se prescinde de su evolución le llevan a interesarse no solamente por la actitud del Estado contemporáneo ante el fenómeno religioso sino también por las relaciones Iglesia-Estado y por los contenidos de la rica tradición del Derecho de la Iglesia. Estos planteamientos conducen a considerar el Derecho Eclesiástico desde la perspectiva de su objeto, y para RUFFINI este objeto aparece regulado por dos fuentes distintas: la Iglesia y el Estado. Esta duplicidad de fuentes es precisamente, según su teoría, la nota distintiva de nuestra disciplina. Su principal aportación estriba en la delimitación que ofrece del Derecho Eclesiástico, como un sistema normativo distinto del Canónico, que comprende tanto el Derecho del Estado sobre la materia eclesiástica como el Derecho religioso vigente en un determinado país ${ }^{31}$. Siguiendo al Profesor MOLANO ${ }^{32}$, RUFFINI representa para el Derecho Eclesiástico italiano dos cosas: el cultivo de esta ciencia según la metodología histórica a la que fue fiel hasta el final de sus días y en la que formó a algunos discípulos que, como JEMOLO, conservarían hasta nuestros días ese gusto por el planteamiento de los problemas dogmáticos desde una perspectiva histórica, y -en segundo lugarla consideración de la libertad religiosa como un derecho subjetivo público cuyo estudio con-

27 «El Derecho Eclesiastico..». 96

28 Il concetto... 70.

29 Lehrbuch des Katholischen und evangelischen Kirchenrechts, traducido al italiano por F. RUFFINI, Trattato di Diritto Ecclesiastico (Torino 1893).

30 «El Derecho Eclesiástico: denominación, origen, evolución y materias que abarca», en Las relaciones entre la Iglesia y el Estado. Estudios en memoria del Prof. P. Lombardia (Madrid 1989) 153-54.

31 F. RUFFINI, «Libertà religiosa e separazione tra Stato e Chiesa», Scritti in onore di Chironi III (Torino 1913); Id., Corso di Diritto Ecclesiastico italiano. La libertà religiosa comme diritto subjetivo (Torino 1934); Id., Scritti giuridici minori: lo studio e il concetto odierno di Diritto Ecclesiastico (Milano 1936); etc. Cf. sobre este punto M.E. OLMOS, «Estado actual de la Ciencia del Derecho Eclesiástico español», ADEE 3 (1987) 202-3: A. REINA y V. REINA, Lecciones de Derecho... 138-39.

32 Introducción a la ciencia... 197 
vierte al Derecho Eclesiástico en una rama jurídica centrada sobre la legislatio libertatis, que tiene en la libertad religiosa su piedra de toque como la primera de las libertades. Y aunque esta orientación de nuestra disciplina se perderá en la Italia de Mussolini, RUFFINI se convierte en precursor de preocupaciones que renacerán posteriormente en la segunda mitad del siglo XX.

Un paso adelante en el desgajamiento del Derecho Eclesiástico del Estado del Derecho Canónico se produce en Italia como consecuencia de la obra de FRANCESCO SCADUTO ${ }^{33}$. Formado en el positivismo jurídico, puede afirmarse que Scaduto es el iniciador de la superación de la concepción unitaria o monista del Derecho Eclesiástico, propia de la escuela histórica del Derecho, de origen alemán, y el iniciador de una concepción dualista del mismo, que va a ser la predominante en Italia. SCADUTO ha sido considerado por la doctrina italiana como el restaurador o el constructor del Derecho Eclesiástico italiano ${ }^{34}$, ya que a él se debe la exposición del concepto moderno del Derecho Eclesiástico, expresión que él mismo utiliza en la prolusión pronunciada en Palermo el 21 de noviembre de $1884^{35}$. En su obra, el autor afirma que las fuentes del Derecho Eclesiástico italiano son de dos especies, eclesiásticas y civiles: «Essendo la Chiesa catholica considerata frai noi come una associazione privata, i cui statuti non sieno stati presentati efficacia giuridica in quanto non contraddicono alle nostre leggi o al Diritto pubblico o alla morale» ${ }^{36}$. Así, admitiendo la dualidad de fuentes del Derecho Eclesiástico, para él resulta más importante la fuente estatal, que cobra cada vez más importancia, a medida que la pierde la fuente eclesial. SCADUTO, pese a haberse formado en el positivismo, no niega la juridicidad de las normas de la Iglesia, simplemente, en su opinión, éstas no son objeto inmediato de estudio del Derecho Eclesiástico en sentido moderno. Los cánones y las decretales regulan las relaciones puramente internas de la Iglesia y evidentemente conservan una gran importancia histórica y sociológica, pero carecen de interés para el jurista laico, a no ser que hayan sido reconocidos directa o indirectamente por el poder civil ${ }^{37}$.

Para él el Derecho Eclesiástico se concibe como el conjunto de normas jurídicas relativas a la materia eclesiástica vigentes en el ordenamiento estatal. Este concepto, a la vez que difiere sustancialmente del propio de la concepción monista, coincide con el defendido por la concepción estatalista, si bien para esta última el concepto de Derecho Eclesiástico agota toda la realidad jurídica relativa a la materia eclesiástica, mientras que para SCADUTO no existe inconveniente alguno para que las normas de la Iglesia sean consideradas como jurídicas por el canonista puro. De esta forma, como señalan los hermanos REINA, «Dcaduto afirma la autonomía y la distinción entre el ordenamiento estatal y el canónico en lugar de la híbrida yuxtaposición y conmixtión que normalmente se producía entre las normas de uno y otro ordenamiento ${ }^{38}$. Es precisamente en este sentido en el que se ha afirmado que es a este autor a quien se debe la primera fijación de los perfiles de la autonomía científica del Derecho Eclesiástico ${ }^{39}$.

33 Diritto Ecclesiastico vigente in Italia, 2 vols. (Napoli 1889 y 1890); Il concetto moderno del Diritto Ecclesiastico (Palermo 1885). Para un análisis de la obra de Scaduto puede verse, además de la bibliografía ya citada, A. DE LA HERA, «La ciencia del Derecho Eclesiástico en Italia», en El fenómeno religioso en España (Madrid 1972) 75-115; G. CATALANO, «Il contributo di Franciesco Scaduto alla nascita ed allo sviluppo del Diritto Ecclesiastico italiano", DE 106 (1995) 845-62.

34 L. DE LUCA, Diritto Ecclesiastico... 90; A.C. JEMOLO, «Francesco Scaduto», Riv. Dir. Pubbl. 25 (1943) 9. Vid. G. CATALANO, «Il contributo di Francesco Scaduto alla nascita ed allo sviluppo del Diritto Ecclesiastico italiano», DE 106 (1995) 845-62.

35 Il concetto moderno... cit.

36 Diritto Ecclesiastico vigente, vol. 1, cit., p. 2.

37 Il concetto moderno..., 14. Cf. J.M. GONZALEZ DEL VALLE, «Contribuciones relativas a la Ponencia Objeto del Derecho Eclesiástico», en Diálogo sobre el futuro de la Ciencia del Derecho Eclesiástico en España (Pamplona 2001) 122.

38 Lecciones de Derecho Eclesiástico... 141.

39 P. LOMBARDIA, «Derecho Eclesiástico y libertad religiosa», Escritos de Derecho Canónico y de Derecho Eclesiástico del Estado 5 (Pamplona 1991) 141. 
En definitiva, y como corolario a este punto, podemos afirmar que la influencia de RUFFINI y SCADUTO en la evolución de la ciencia tanto canonista como eclesiasticista italiana fue decisiva. Utilizando las palabras magistrales con que A. DE LA HERA ha sintetizado las distintas posturas de estos maestros, mientras Ruffini consideró siempre al Derecho Eclesiástico como un amplio conjunto donde se reúnen la historia de las fuentes y de cada institución, el Derecho emanado de la Iglesia católica y el Derecho de todos los Estados sobre materias eclesiásticas tocante tanto a los católicos como a las restantes confesiones religiosas, Scaduto estimaba que el Diritto Ecclesiastico, como ciencia, tenía como único objeto el estudio de las normas vigentes sobre materias eclesiásticas dictadas por los Estados o reconocidas por ellos $o$, al menos, no en contradicción con los ordenamientos estatales, y que como disciplina docente ese estudio había de limitarse al de tales normas vigentes en el país concreto donde la enseñanza se impartiese ${ }^{40}$. No obstante, pese a las diferencias evidentes entre el pensamiento de los dos grandes maestros, en sus primeros estadios coincidieron en algunos extremos ${ }^{41}$ : en primer lugar, ambos trataban tanto las normas canónicas como las estatales, si bien aquellas sólo en cuanto necesarias para la comprensión de éstas; en segundo lugar, los dos mantenían una actitud antieclesiástica y anticlerical, motivada por el liberalismo y la situación política italiana del momento; por último, las dos posturas estaban influidas por las teorías que defienden que la juridicidad proviene del poder del Estado.

Una buena parte de la doctrina italiana intentó repetidamente encontrar una conciliación entre las dos posturas. Esta tendencia a conciliar la concepción de RUFFINI y SCADUTO resultó particularmente sensible en NICOLA COVIELLO ${ }^{42}$. Según el conocido profesor de Catania, por Derecho Eclesiástico se debe entender el conjunto de normas jurídicas que se refieren a las personas, las cosas y los actos de la Iglesia Católica, pero por otro lado distingue netamente el Diritto Ecclesiastico dello Stato y el Diritto Ecclesiastico della Chiesa, que denomina Derecho Eclesiástico en sentido propio ${ }^{43}$. Y concluía que, no obstante la distinción entre los dos sistemas de normas, es necesario estudiar tanto uno como el otro, porque no se puede comprender el Derecho Eclesiástico del Estado sin conocer bien el Derecho Eclesiástico de la Iglesia. Esta postura ha sido definida por DE LUCA como un intento de conciliación entre la concepción monista y la concepción propia de SCADUTO, operada mediante la distinción entre un concepto amplio, didáctico, del Derecho Eclesiástico, correspondiente a la concepción monista ruffiniana, y un concepto jurídico del mismo, propio de SCADUTO.

\section{LA TEORÍA DE LA PLURALIDAD DE LOS ORDEMANIENTOS JURÍDICOS DE SANTI ROMANO}

La máxima contribución a la consolidación de la concepción dualista del Derecho Eclesiástico viene definitivamente configurada con la teoría de la pluralidad de ordenamientos jurídicos de SANTI ROMANO, que constituye la base de la moderna concepción de las fuentes del Derecho Eclesiástico ${ }^{44}$. Con él se va a superar decididamente el estatalismo normativista y la consiguiente consideración del Estado como única fuente del Derecho. El pone de mani-

$40 \quad$ Introducción a la Ciencia del Derecho canónico (Madrid 1978) 115.

41 A. DE LA HERA, ob. cit. p. 116-17.

42 Cf. al respecto, L. DE LUCA, Diritto Ecclesiastico... 93.

43 Corso di Diritto canonico (Palermo 1903-1904)4; Id., Manuale di Diritto Ecclesiastico a cura di V. Del Giudice, vol. 1, Parte Generale (Roma 1915) 1 ss.

44 J.M. GONZALEZ DEL VALLE, «El Derecho Eclesiástico: denominación, origen, evolución y materias que abarca», Las relaciones entre la iglesia y el Estado. Estudios en memoria del profesor P. Lombardia (Madrid 1989) 154-55, nota 8. La aportación de la obra de SANTI ROMANO a la Ciencia del Derecho Eclesiástico ha sido magistralmente analizada por F. FINOCCHIARO, en «Santi Romano e il Diritto Ecclesiastico», DE 86 (1975) $173-87$. 
fiesto «la tendencia de una numerosa serie de grupos sociales a constituirse un ámbito jurídico independiente» ${ }^{45}$. La Iglesia, para él, no es una mera asociación privada sino una institución ${ }^{46}$, y su Derecho no deriva de un vínculo contractual sino de la subordinación de los fieles a la institución. El poder de la Iglesia, especialmente espiritual, no deriva del Estado, sino que es originario; la Iglesia, que tiene una potestad originaria, está dotada de autonomía. Como consecuencia, el autor afirma que la eficacia del Derecho Canónico es de Derecho objetivo y no deriva de la eficacia que el Estado le atribuya sino de su propia naturaleza. El Estado lo único que hace es reconocerlo ${ }^{47}$.

Con esta teoría de la pluralidad de los ordenamientos jurídicos se estaban sentando ya las bases para la definitiva distinción entre el ordenamiento de la Iglesia y el ordenamiento del Estado sobre la materia eclesiástica. Así, según SANTI ROMANO, éstos «son dos diversos y distintos ordenamientos que tienen una propia esfera, fuentes propias, una propia organización, sanciones propias y no constituyen el uno junto al otro una verdadera unidad. Se trata de dos mundos jurídicos, uno de los cuales puede influir materialmente sobre el otro pero jurídicamente distintos y autónomos» ${ }^{48}$. Es más, según él, «el Derecho Eclesiástico considerado en su conjunto no es sólo un ordenamiento sino que comprende varios ordenamientos jurídicos que tienen entre sí puntos de contacto variadísimos, puesto que son distintos» ${ }^{49}$

\section{LA ESCUELA DOGMÁTICA ITALIANA Y EL DESARROLLO POSTERIOR DEL DERECHO ECLESIÁSTICO}

El paso decisivo en la distinción entre la Ciencia del Derecho Canónico, como ordenamiento jurídico de la Iglesia, y la Ciencia del Derecho Eclesiástico, como rama del ordenamiento jurídico del Estado cuyo objeto es la regulación del fenómeno religioso, se producirá con la obra de VICENZO DEL GIUDICE, MARIO FALCO y ARTURO CARLO JEMOLO, y se consolidará al adquirir sendas disciplinas autonomía didáctica en las facultades estatales italianas, a la vez que se restauraba la enseñanza del Derecho Canónico, separadamente del Derecho Eclesiástico.

FALCO persiguió, siguiendo la tesis propuesta por SCADUTO, liberar a la disciplina del Derecho Eclesiástico de sus presupuestos históricos y otorgar una atención prioritaria al sistema jurídico vigente. Se trata de desarrollar simultáneamente los dos sistemas jurídicos, Eclesiástico y Canónico, por obra de un mismo especialista que ha de dominar ambos campos del saber jurídico. Así, según FALCO, ha de exponerse en la cátedra el Derecho vigente Canónico y Eclesiástico ${ }^{50}$, y por esta razón su Corso di Diritto Ecclesiastico aparece ya dividido en dos partes, una primera de Diritto Canonico y otra segunda de Diritto Ecclesiastico italiano. De ahí que podamos afirmar que nos encontramos ya ante el «fenómeno del desdoblamiento de la única disciplina del Derecho Eclesiástico en dos» ${ }^{51}$.

Por Real Decreto de 2 de octubre de 1924 se aprobó la creación de la primera cátedra de Derecho Canónico, en la Universidad católica del Santo Cuore de Milán. Quedaba consagrada de esta forma la separación de la enseñanza del Derecho Eclesiástico y del Derecho Canónico en la Universidad italiana. Y fueron precisamente los propios eclesiasticistas los que devolvieron al Derecho Canónico el lugar que había ocupado y perdido en la enseñanza

L'ordinamento giuridico. Studi sul concetto, le fonti e $i$ caratteri del Diritto (Pisa 1918) 102.

46 S. ROMANO, Lezioni di Diritto Ecclesiastico (Pisa 1912) 47.

47 Ibid., p. $50 \mathrm{~s}$.

48 L'ordinamento giuridico... 108.

49 Ibid., p. 98.

50 Corso di Diritto Ecclesiastico (Padova 1930) 7-8.

51 A. DE LA HERA, «La Ciencia del Derecho Eclesiástico en Italia», p. 97. 
universitaria. En la creación de la cátedra de Derecho Canónico ejerció una influencia decisiva VICENZO DEL GIUDICE ${ }^{52}$. Aplicando la teoría de la pluralidad de los ordenamientos jurídicos de Santi Romano, DEL GIUDICE parte de la distinción neta entre el Derecho Canónico y el Derecho Eclesiástico, que para él son dos sistemas jurídicos distintos, dos diferentes ordenamientos, que requieren también dos tratamientos científicos diversos. Pero según él el Derecho Eclesiástico no puede concebirse como un Derecho de exclusiva e inmediata derivación estatal sino que comprende también las normas de derivación confesional —católicas o acatólicas - que tienen vigencia en el ámbito estatal por voluntad misma del Estado.

Por su parte, ARTURO CARLO JEMOLO ${ }^{53}$, seguidor de RUFFINI, defiende que nuestra disciplina está constituída por dos sistemas orgánicos de normas jurídicas, distintos entre sí, el Derecho de la Iglesia y el Derecho del Estado. Según él no es posible reconducirlos a una unidad, a un sistema único ${ }^{54}$. Para él el concepto de Derecho Eclesiásto, que engloba los dos conceptos jurídicos, el de Derecho de la Iglesia y el de Derecho del Estado, es sólo un concepto didáctico. Así, siendo distintos estos dos conceptos, él considera que puede adoptarse el término Diritto della Chiesa para el Derecho emanado de la Iglesia y Diritto Ecclesiastico dello Stato para el Derecho del Estado en materia religiosa, y reserva el término «Diritto Ecclesiastico, senz'altre specificazioni, ad indicare la disciplina che abbraccia lo studio dei due ordinamenti giuridici» ${ }^{55}$. JEMOLO define el Derecho Eclesiástico como aquella rama del Derecho del Estado que tiene por objeto el estudio de la legislación relativa a los cultos, es decir, aquella rama del Derecho Público del Estado que estudia las normas del ordenamiento jurídico referentes a las confesiones religiosas ${ }^{56}$.

Esta orientación dogmático-jurídica de la doctrina italiana posterior, como ha podido ya deducirse, se apoya sobre las siguientes bases: la separación entre la historia y la dogmática defendida sobre todo por FALCO; la aceptación del carácter jurídico del Derecho Canónico, con independencia del Derecho Eclesiástico y del Derecho italiano; por último, la imposición del criterio didáctico de que debe tratarse separadamente en la cátedra, cada ordenamiento jurídico, diferenciando así dos partes en la cátedra del Derecho Eclesiástico, una de Derecho Canónico y otra segunda de Derecho Eclesiástico del Estado ${ }^{57}$. A partir de este momento, la ciencia del Derecho Eclesiástico adquirirá un notable grado de desarrollo en Italia, que será decisivo en la influencia que con posterioridad ejercería en la evolución y la consolidación de la ciencia del Derecho Eclesiástico en España.

Y si, como hemos visto, en una primera etapa el Derecho Eclesiástico italiano estuvo marcado por la doble dirección metodológica de Ruffini y Scaduto, la teoría de los ordenamientos jurídicos de Santi Romano y la firma de los Pactos de Letrán entre el Estado italiano y la Santa Sede en 1929 favorecieron el inicio de una segunda etapa, que vendría marcada por la orientación institucional del Derecho Eclesiástico del Estado, centrándose la temática objeto de su estudio en las relaciones institucionales Iglesia-Estado, primero, y con posterioridad en

52 Un estudio de la obra de DEL GIUDICE puede verse en P. LOMBARDIA, «Aportaciones de Vicenzo Del Giudice al estudio sistemático del Derecho canónico», IC 2 (1962) 289-325, traducido al italiano por F. CONTADINI, «Contributi di Vicenzo Del Giudice allo studio sistematico del Diritto canonico» DE 74 (1963) 3-48.

53 La aportación de A.C. JEMOLO ha sido sintetizada, entre otros, por P. GISMONDI, «Jemolo, lo studioso di Diritto Ecclesiastico», DE 93 (1982) 17-24; L. DE LUCA, «Jemolo canonista», ibid., p. 25-32; L. SPINELLI, «I rapporti tra Stato e Chiesa nella dottrina di Jemolo», ibid., 33-39.

54 «Vano è ogni tentativo per ricondurre ad unità organica e fondere in unico sistema questi due complessi di norme»: A.C. JEMOLO. Elementi di Diritto Ecclesiastico (Firenze 1927) 13.

55 Ibid., p. 19

56 Es aquella rama del Derecho público del Estado «che ha ad oggetto lo studio delle norme dell'ordinamento giuridici concernenti le confessioni religiose: il modo con cui lo stato le considera, le condizioni cui sottopone il riconoscimento degli enti che sorgono in senso ad esse, le regole cui vuole sottostia la loro attività, il valore che attribuisce a determinati loro atti»: Corso di Diritto Ecclesiastico (Roma 1945) 3. Cf. asímismo, Lezioni di Diritto Ecclesiastico (Milano 1961) 23-26.

57 A. DE LA HERA, Introducción a la Ciencia... 117. 
las relaciones entre el ordenamiento estatal con los ordenamientos de las confesiones religiosas, pasando así a convertirse en el eje del Derecho Eclesiástico del Estado, en diversos países católicos, el Derecho concordatario. Hacia mediados de siglo asistimos a un proceso de individualización del Derecho Eclesiástico, propiciado por el movimiento internacional en favor del reconocimiento de los derechos humanos. La caída de la Monarquía y del Fascismo en Italia, y la entrada en vigor de la Constitución republicana de 1 de enero de 1948, unidos a la proclamación del derecho de libertad religiosa por la Declaración Universal de Derechos Humanos de las Naciones Unidas, en 1948, y en el Convenio Europeo para la Protección de los Derechos Humanos y las Libertades Fundamentales de 1950, firmado precisamente en Roma, constituyeron factores determinantes en esta evolución, hasta tal punto de llegase a concebir nuestra disciplina como una legislatio libertatis.

En España, aunque la construcción de una Ciencia del Derecho Eclesiástico se inició en la década de los años cuarenta ${ }^{58}$, de la existencia de un Derecho Eclesiástico como rama científica autónoma del Derecho del Estado, con un cuerpo de doctrina reconocido, solamente puede hablarse desde los años setenta ${ }^{59}$. Hasta ese momento, el ordenamiento español se remitía en bloque, en materia religiosa, al Derecho de la Iglesia católica, de forma que, la función que en otros países desempeñaba el Derecho Eclesiástico, en España era desempeñada por el lus Publicum Ecclesiasticum Externum ${ }^{60}$. De modo similar a la evolución que experimentó la disciplina en Italia, durante el régimen del General Franco la normativa relativa al fenómeno religioso se limitó a regular las relaciones del Estado con la Iglesia Católica. Los estudios doctrinales de la época, realizados por canonistas, se centraban en el estudio del Derecho concordatario, concretamente del concordato firmado con la Santa Sede en 1953, y de las normas que el legislador español había emanado, en aplicación del mismo, para regular el estatuto jurídico de la Iglesia Católica. La Declaración Conciliar Dignitatis Humanae, de 1965, y la posterior promulgación en España, de la Ley de Libertad Religiosa, de 1967, constituyeron un acicate importante para que la canonística comenzara a fijarse en el derecho de libertad religiosa, como derecho innato a la dignidad de la persona humana, aunque hay que esperar a los años 70 para que los planteamientos ya consolidados en Italia comenzaran a encontrar alguna receptividad en España.

Sin duda alguna los dos acontecimientos que han contribuido de forma más significativa al impulso de la Ciencia del Derecho Eclesiástico en España han sido la promulgación de la Constitución de 1978 y la Ley Orgánica de Libertad Religiosa de 1980. La nueva situación jurídico-política en España dio paso a una nueva actitud del Estado y los poderes públicos ante el fenómeno religioso, por imperativo del art. 16 del texto constitucional, precepto en el que han quedado consagrados los principios que, a partir de ese momento, informarán el Derecho Eclesiástico en España ${ }^{61}$.

Lourdes Ruano Espina

Área de Derecho Eclesiástico del Estado

Facultad de Derecho de la Universidad de Salamanca

37007 Salamanca

58 P. LOMBARDIA, «Presentación» a la obra de JJ. AMOROS, La libertad religiosa en la Constitución Española de 1978 (Madrid 1984) 14.

59 Cabe señalar que ya desde el volumen 3 de la Revista Española de Derecho Canónico, en el año 1948, aparece una sección que lleva por epígrafe «Reseña de Derecho del Estado sobre materias eclesiásticas», y que inicialmente estuvo a cargo del Profesor Maldonado. Pero cuando se plantea por vez primera en España la explicación del Derecho Eclesiástico en las Facultades de Derecho, como materia con cierta entidad y autonomía fue en el Coloquio sobre metodología Universitaria del Derecho Canónico celebrado en Salamanca los días 1 y 2 de octubre de 1969, a propuesta del Profesor Portero Sánchez. Puede verse la reseña que acerca de dicho coloquio publicó la Revista Española de Derecho Canónico, a cargo del P. Juan A. Eguren (REDC 25, 1969, especialmente p. 742).

60 Ivan C. Iban, «Derecho Eclesiástico y Derecho Canónico» ADEE 3 (1987) 328-29.

61 Cf. L. RUANO ESPINA, «La regulación del fenómeno religioso y la enseñanza del Derecho Eclesiástico del Estado», Derecho y Opinión 9 (2001). 